\title{
Return to work after vocational rehabilitation: does mindfulness matter?
}

This article was published in the following Dove Press journal:

Psychology Research and Behavior Management

26 February 2014

Number of times this article has been viewed

\section{Solveig Vindholmen' \\ Rune Høigaard ${ }^{2}$ \\ Geir Arild Espnes ${ }^{3}$ \\ Stephen Seiler ${ }^{4}$}

'Department of Psychosocial Health, Faculty of Health and Sport Sciences, University of Agder, Kristiansand, Norway; ${ }^{2}$ Department of Public Health, Sport and Nutrition, Faculty of Health and Sport Sciences, University of Agder, Kristiansand, Norway; ${ }^{3}$ Research Centre for Health Promotion and Resources, Department of Social Work and Health Science, Norwegian University of Science and Technology, Trondheim, Norway; ${ }^{4}$ Faculty of Health and Sport Sciences, University of Agder, Kristiansand, Norway
Correspondence: Solveig Vindholmen Faculty of Health and Sport Sciences, University of Agder, PO box 422, NO-4604 Kristiansand, Norway $\mathrm{Tel}+4799460380$

Email solveig.vindholmen@uia.no
Purpose: Mindfulness has become an important construct in return-to-work (RTW) rehabilitation. The aim of this study was to investigate whether mindfulness is a predictor for RTW, and to examine the indirect effect of mindfulness on RTW and work ability through quality of life (QOL).

Methods: A retrospective study was conducted among 80 former participants $(71$ females and seven males) from age 24 to 66 , in a multidisciplinary vocational rehabilitation program (MVRP). Self-report questionnaires were used to measure work status, work ability, QOL, and mindfulness. Demographic data were also collected.

Results: In the current sample, $47 \%$ of participants reported having returned to ordinary work. The majority of the non-working sub-sample reported being in work-related activity or education A bias-corrected bootstrapping technique was used to examine indirect effects. Results revealed that mindfulness was indirectly related to both RTW and work ability through QOL. There was no significant total effect of mindfulness on work ability or RTW. Logistic regression analysis was performed to assess the impact of mindfulness on the likelihood that respondents returned to work. None of the independent mindfulness variables (observe, describe, act aware, nonjudge, non-react) made a unique statistically significant contribution to the model. The covariates work ability and education level significantly predicted RTW. However, when the data were analyzed after stratification by education level, the "observation" facet of mindfulness made a significant contribution to the model (odds ratio $=1.28$, confidence interval $=1.03-1.59$ ) for "high educated" participants.

Conclusion: These data suggest that mindfulness may enhance RTW and work ability through QOL. Furthermore, for "high educated" participants the observation facet of mindfulness significantly predicted RTW.

Keywords: work ability, quality of life, multidisciplinary, mindfulness, return to work, vocational rehabilitation

\section{Introduction}

Sick leave is a phenomenon that varies both over time and among different groups. There has been a dramatic increase in sick-leave rates in the working-age population over the last 30 years. ${ }^{1}$ Musculoskeletal pain, depression, and anxiety cause the majority of all sick leave, and comorbidities are prevalent. ${ }^{2,3}$ Long-term sick leave represents a major economic burden for society, and affected individuals risk financial hardship and social exclusion ${ }^{4,5}$ in addition to increased risk of permanent exclusion from working life through forced retirement due to ill health. ${ }^{5,6}$ Sick leave is a complex phenomenon, and there is no unified theory or consensus regarding the mechanisms leading to longterm sick leave. ${ }^{7}$ Prognostic factors for return to work (RTW) after sick leave vary depending on diagnosis, duration of symptoms and sick leave, and whether or not a 
rehabilitation program has been performed. ${ }^{8-13}$ Methods for preventing and "treating" sick leave vary among countries. Multifactorial vocational rehabilitation programs (MVRPs) are suggested as one method for bringing individuals back to work faster. ${ }^{14,15}$ Some MVRPs give mindfulness training considerable attention, and thereby suggest mindfulness training as a potential tool for bringing people back to work after long-term sick leave.

RTW is a complex, multifactorial process, influenced by individual, social, economic, and work-related factors, and indeed not only related to medical health factors. ${ }^{16,17}$ Vocational rehabilitation is aiming to improve work ability, ${ }^{18}$ on order to enhance RTW rates. Previous research has identified work ability to be a strong predictor for successful RTW after an MVRP. ${ }^{19}$ Moreover, researchers have demonstrated the positive association between quality of life (QOL) and RTW. Sjöstrom et $\mathrm{al}^{20}$ investigated 40 women and 20 men who had participated in an MVRP, finding that at 2-year follow-up, the majority of the participants reported increased QOL compared with baseline, and most participants had returned to work. Later, Lydell et $\mathrm{al}^{21}$ examined psychosocial factors in individuals who had participated in a rehabilitation program 10 years prior, and compared results from individuals who achieved successful RTW with sick-listed individuals. The "returned to work" group showed a significantly higher QOL. Furthermore, two qualitative studies ${ }^{22,23}$ explored experiences and reflections from ten individuals who had participated in the particular MVRP examined in this study, and the individuals reported improved QOL both directly after the completed program ${ }^{22}$ and at follow-up one year after. ${ }^{23}$ The connection between mindfulness training and improved QOL is well established. ${ }^{24}$ However, to our knowledge, the associations between mindfulness and work ability and RTW through QOL have not yet been investigated. Indeed, the association between mindfulness and work ability is sought after. ${ }^{24}$

One acknowledged definition of mindfulness is "paying attention on purpose in the present moment and nonjudgementally." 25 To be mindful, individuals must be alert to the present moment and not absorbed with thoughts about the past or the future. ${ }^{26,27}$ Mindfulness involves paying attention to both external (environmental) and internal (intrapsychic) phenomena. ${ }^{28}$ Moreover, achieving a mindful state is an inherent human capacity ${ }^{29}$ and requires dis-identification from mind. ${ }^{30,31}$ Shapiro et $\mathrm{al}^{30}$ proposed that the fundamental psychological mechanism of mindfulness is reperceiving. Reperceiving is defined as a shift in perspective characterized by being able to step back from and be less identified with one's thoughts and emotions. One mindfulness program that has received considerable research attention is Mindfulness Based Stress Reduction (MBSR), ${ }^{32}$ which was developed to help people cope with stress. ${ }^{33,34}$ The practice of mindfulness in the form of MBSR encompasses sitting meditation, body scan, hatha yoga, and practicing being present in everyday moments. ${ }^{32}$ Research has shown that mindfulness enhances both physical and mental health. ${ }^{27}$ Several studies have reported symptom improvement associated with mindfulness practice (MBSR), such as: reduced depression and anxiety:35-37 increased pain tolerance ${ }^{38,39}$ decreased stress and burnout; ${ }^{40}$ and improved psychological functioning. ${ }^{36,38,41}$ A recent meta-analysis of the research literature ${ }^{24}$ reported robust effect sizes for the impact of MBSR on a number of measures of mental health for numerous target groups. Moreover, enhanced mindfulness is reported to improve both QOL, personal development such as empathy and coping, and some aspects of somatic health. However, De Vibe et $\mathrm{al}^{24}$ concluded that very few studies measure the impact of MBSR on work ability, and that there is a lack of data on long-term effects.

The Norwegian Labor and Welfare Administration (NLWA) uses mindfulness as a tool in vocational rehabilitation. Mindfulness in the form of $\mathrm{MBSR}^{32}$ is one of the main components in a nationally established MVRP. The program is funded by NLWA and is offered to people on sick leave and people with self-reported decreased work ability, with the goal of increasing work ability and RTW. When the MVRP was introduced in Norway in 2007, it was reserved for people who had been on sick leave for less than 1 year. From 2009, other users of NLWA were offered this rehabilitation program when reporting reduced work ability. Thus, mindfulness is being increasingly used as a tool to treat many of the psychological and physical conditions that are associated with long-term sick leave. However, research evidence supporting this specific connection between mindfulness training as an intervention and improved work ability and RTW is lacking. Some qualitative studies have been conducted to explore the relationship between self-awareness and work ability. ${ }^{42}$ Some studies have also explored the impact of mindfulness on work related issues such as burnout ${ }^{40,43}$ and work performance. ${ }^{44,45}$ Yet, surprisingly little is known about how mindfulness directly and indirectly affects the likelihood of successfully returning to work after long-term sick leave. The aim of this study was therefore twofold: 1) to investigate whether mindfulness is a positive predictor of RTW; and 2) to examine the indirect effect of mindfulness on RTW and work ability through QOL. The hypothesized model is illustrated in Figure 1. 


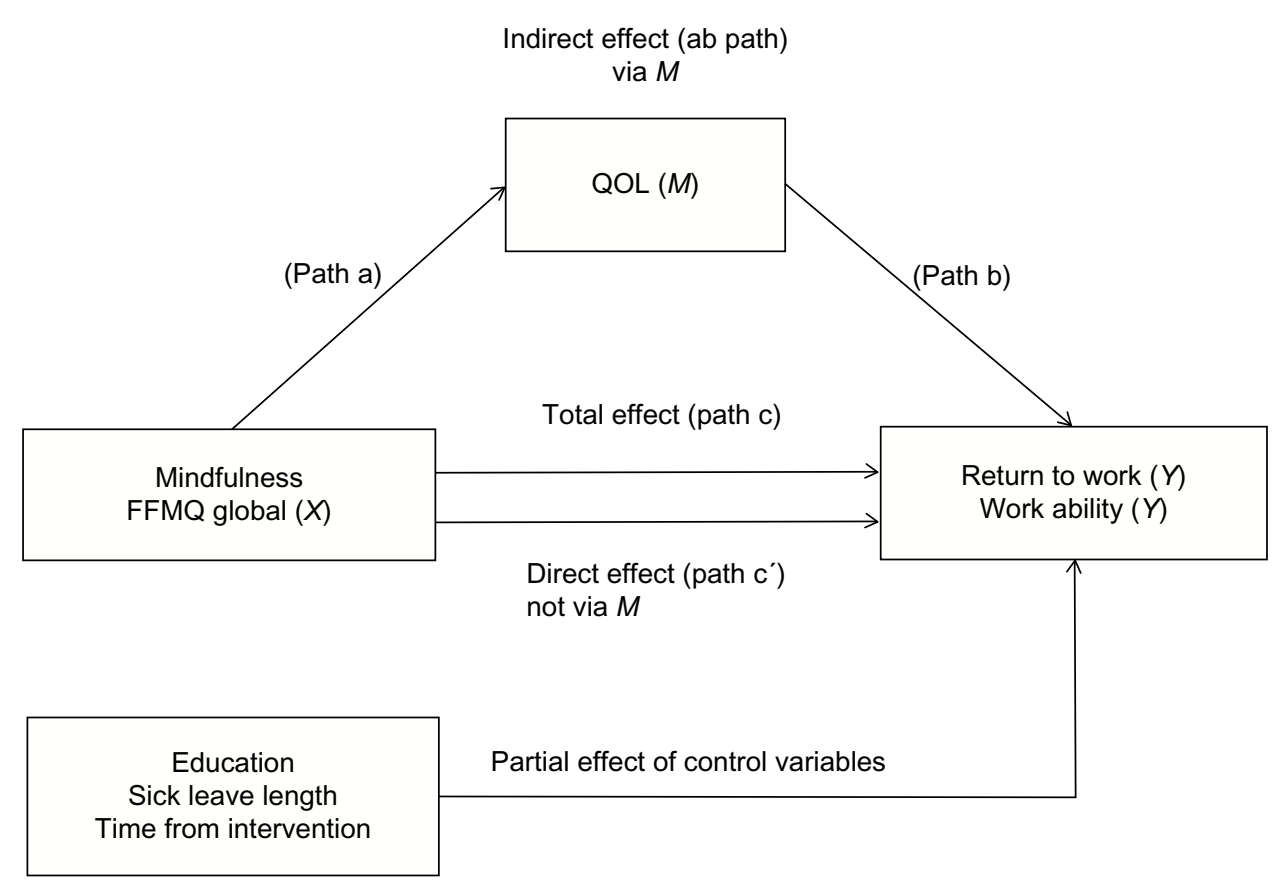

Figure I The hypothesized simple mediation model (conceptual model number 4 in Hayes'46 "Process").

Abbreviations: FFMQ, Five Facet Mindfulness Questionnaire; $M$, the proposed mediator; $X$, the predictor variable; $Y$, the predicted variable; QOL, quality of life.

\section{Method}

\section{Participants}

In this retrospective study, the sample consisted of 80 individuals aged 24-66 (mean age 47; standard deviation [SD] 9). Most of the participants were women (91\%). All participants had completed a 4-8-week MVRP at a modern vocational rehabilitation enterprise in South Norway in the time period 2008-2011. At the time of participating in the MVRP, the subjects were on longterm sick leave or had reported decreased work capacity. Examples of the most common jobs in the present sample were nurse, auxiliary nurse, teacher, teacher assistant, pre-school teacher, and office worker/clerical assistant. In the sample, 45 participants (56\%) were employed and 35 participants (44\%) were unemployed at the time of participation in the study.

\section{Intervention}

The MVRP consisted of 4-8-week intensive period, where the participants attended approximately 6 hours/day, 3 days per week. All participants were assigned to the MVRP by NLWA, who also decided how long each participant was allowed to participate in the program, individual needs taken into consideration. The team of supervisors was composed of workers with different professional backgrounds (eg, nurses, teachers, physiotherapists, and occupational therapists). All had post-qualifying education obtained while working at the vocational enterprise. The content of the MVRP was arranged into three categories:

1. Educational program - this component was based on a group-learning program for people with chronic musculoskeletal pain developed and described by Haugli and Steen. ${ }^{47,48}$ The educational program has four cornerstones: 1) mindfulness training; ${ }^{32}$ 2) confluent education methods, ${ }^{49}$ 3) phenomenological understanding of the body; ${ }^{50}$ and 4) empowering, ie, awareness of personal resources.

2. Physical activity - comprehensive and varied physical activities were applied in the program, aiming to enhance functional strength and core stability, balance, coordination, and overall endurance and strength. Physical activities applied in the MVRP were hatha yoga, cycle ergometer spinning, basic strength and endurance training, and psychomotor physiotherapy. The participants were encouraged to listen to their body, take a break when needed, and not overextend themselves. In this way, the physical activities were used as exercises in challenging personal limits, learning to respond to body signals, and adjusting effort level when needed.

3. Individual counseling - participants were offered individual counseling based on cognitive therapy ${ }^{51}$ every second week (three meetings in total), plus one individual counseling session in psychomotor physiotherapy ${ }^{52,53}$ and one counseling session with a sport supervisor whenever 
an individual exercise program was preferred by the participant. Moreover, the participants were offered assistance to communicate their needs to the employer (for employed participants) or to the NLWA (for the unemployed participants).

\section{Procedure}

All former participants in the MVRP were invited to participate in the study $(\mathrm{N}=200)$, and 80 individuals accepted (40\% response rate). The participating sample did not differ from nonparticipants in basic demographic characteristics. All participants were volunteers and gave their informed consent. Confidentiality was emphasized. This study was approved by the national ethics committee, Health Region South, and the Norwegian Social Science Data Service (NSD).

All participants answered a self-report questionnaire. Baseline data on whether or not the participants had been entitled to a sickness benefit were extracted from the vocational enterprises database. To be entitled to the sickness benefit in Norway, individuals must have stayed at work for 4 weeks or more. Moreover, benefits confer the right to receive a regular salary of $100 \%$ of wages, for a maximum of 248 days while sick. ${ }^{54}$

\section{Instruments}

\section{Mindfulness}

All participants completed the Norwegian version ${ }^{55}$ of the Five Facet Mindfulness Questionnaire (FFMQ), ${ }^{56}$ which assesses five facets of a general tendency to be mindful in daily life: observing, describing, acting with awareness, nonreactivity to inner experience, and non-judging of inner experience. Examples of items are: "observing" facet, "I notice the smells and aromas of things"; "describing" facet, "I am good at finding words to describe my feelings"; "acting with awareness" facet, "I find myself doing things without paying attention" (scale reversed); "non-judging of inner feelings" facet, "I think some of my emotions are bad or inappropriate and I should not feel them" (scale reversed); and "nonreactivity to inner experience" facet, "I perceive my feelings and emotions without having to react to them." The "nonreactivity to inner experience" facet consists of seven items, all other facets have eight items each. Items are rated on a fivepoint Likert-type scale ranging from 1 (never or very rarely true) to 5 (very often or always true). Psychometric support for the measure was derived from analysis in Dundas et al. ${ }^{55}$

\section{Present work and benefit situation}

Four questions measured the participants' present work and benefit situation. Question 1, 2, and 4 were derived from a questionnaire developed by a national group of occupational researchers and practitioners, aiming to obtain a standardized outcome measure to the MVRP in Norway (M Eftedal, personal communication, May 2011).

Question 1 measured RTW rates after completing the rehabilitation program: "After the vocational rehabilitation program I returned, partly or mainly, back to work ..." Responses were categorized as: 1) "Immediately, or within fourteen days;" 2) "Within one month;" 3) "Within two months;" 4) "Within three months;" 5) "Within six to twelve months;" and 6) "Have not yet returned to work."

Question 2 assessed the participants' present work and benefit situation, using a list of eleven statements: 1) "I am working, mainly or partly;" 2) "I am on sick leave, mainly or partly;" 3) "I participate in work preparatory training;" 4) "I participate in rehabilitation;" 5) "I receive work assessment allowance;" 6) "I take education;" 7) "I am active job seeker;" 8) "I receive disability benefit;" 9) "I have applied for disability benefit;" 10) "Other measures. Specify: ...;" and 11) "Other allowances. Specify: ..." The participants were told to mark all the statements that were true about their present situation.

Question 3 assessed the participants' main source of income, using the categories: 1) "ordinary salary," 2) "sick leave benefit," 3) "work assessment allowance," and 4) "Other."

Question 4 measured whether or not the participants were employed: "Are you currently employed?" The respondents were given the alternatives: "yes" or "no."

\section{Work ability}

One question, the first item from Work Ability Index ${ }^{57}$ was used to measure the participants' work ability: "Current work ability compared with the lifetime best." Possible responses ranged from 0 "completely incapable to work" to 10 "My best work ability ever." The item is being termed "work ability score," and is reported to validly measure work ability of people on long-term sick leave ${ }^{58}$ and workers. ${ }^{59}$

\section{QOL}

A single-item measure, named Cantrils' ladder, ${ }^{60}$ the here and now dimension, was used to measure the participants' QOL. The scale is depicted as a ladder, and the participants were asked to rate their sense of present wellbeing, ranging from 1 "Worst possible life," marking the bottom of the 
ladder, to 10 "Best possible life," marking the top of the ladder. The Cantrils' ladder is considered a general scale with good psychometric properties. ${ }^{61}$

\section{Education}

One question assessed education level: "Please tick in the appropriate box your highest education completed." Possible responses were: 1) "Did not complete primary school," 2) "Primary school," 3) "High school," 4) "University bachelor degree or lower," or 5) "University master degree or higher." In all analyses, the variable "education" was dichotomized between high education (university level) and low education (high school or lower).

\section{Sick-leave length}

The variable "sick-leave length" quantified whether or not the participants at the beginning of the MVRP received a sickness benefit. The vocational enterprise had information about this on file, and we received this information from their database. Participants not entitled to sickness benefit have either been on sick leave more than 1 year, or they have not obtained the entitlement because they have not been in an ordinary job for 4 weeks or more. In this study, most participants without sickness benefit received work assessment allowance.

\section{Time from intervention}

To assess time from intervention, the participants were asked: "When did you participate in the MVRP at the vocational enterprise?" Possible responses were "Spring" or "Autumn" and "Year."

\section{Statistical analyses}

Data were analyzed using SPSS (IBM Corporation, Armonk, NY, USA) for Windows (version 19.0). Frequency, percentage, mean value, and standard deviation were calculated for continuous and categorical variables. A $P$-value of $<0.05$ was considered statistically significant. The reliability of the scales was assessed by calculating Cronbach's alpha coefficient. A global mindfulness score (FFMQ global) was calculated by adding up the five facets of mindfulness and dividing the sum by five. To test whether there were significant differences between groups in any facet of FFMQ, independent $t$-tests were performed.

The dichotomous variable RTW was created based on responses to "Present work and benefit situation." Participants were categorized into two groups: "returned to work" or "not returned to work." Work status and source of income in the sample indicated a complexity in benefit systems and work activity, important in differentiating RTW rates. In this study, only the participants reporting ordinary salary as main income were defined as "returned to work" $(\mathrm{N}=38)$. Participants who reported receiving work assessment allowance or disability benefit as their main income were defined as "not returned to work" $(\mathrm{N}=42)$, even if they were in work-related activity or education. One participant reported working $30 \%$ in an ordinary job, receiving work assessment allowance as main income, and was categorized in the group "returned to work."

Direct logistic regression was performed to assess the impact of mindfulness on the likelihood that respondents would report that they had returned to work. Preliminary analyses were conducted to ensure no violation of the assumptions of normality, linearity, multi-co-linearity, and homoscedasticity. The initial selection of potential independent predictors to the model were selected by entering one variable at a time in the logistic regression analysis, and were accepted if $P<0.20$. The five facets of mindfulness were tested for inclusion in the model. Moreover, previous research has identified associations between RTW and age, ${ }^{62}$ sex, ${ }^{63}$ education, ${ }^{64}$ work ability, ${ }^{19}$ time from intervention, and sick-leave length, ${ }^{65}$ and these variables were also tested for inclusion in the model as potential covariates. Seven independent variables were ultimately accepted in the final model: FFMQ observation, FFMQ describe, FFMQ act aware, work ability, education, time from intervention, and sick-leave length.

To explore whether the construct of mindfulness influenced RTW rates differently in the "high education" group and in the "low education" group, logistic regression analysis was performed with the sample stratified on high/low education level. The model contained three independent mindfulness variables: "FFMQ observation," "FFMQ describe," and "FFMQ act aware."

Hayes" ${ }^{46}$ macro-application "Process" for SPSS was used to test the hypothesized model (Figure 1) examining indirect, direct, and total effects. "Process" 46 uses a regressionbased approach for estimating various effects of interest in mediation, moderation, and conditional process analysis. Conceptual model number 4 (Appendix A in Hayes'46 "Process") was used to examine the hypothesized simple mediator model (Figure 1) in this study. This procedure generates indirect, direct, and total effects in a simple mediator model, ${ }^{66}$ with the inclusion of covariates. "Process" 46 produces bootstrap estimates and bias-corrected (BC) confidence intervals (CIs) for the indirect effect. Moreover, a BC CI that does not cross zero indicates a statistically significant indirect 
effect. In this study, a 95\% CI was constructed on the basis of 5,000 bootstrap estimates. In addition to normal theory regression procedures, Preacher and Hayes ${ }^{67}$ recommend a BC bootstrapping technique to examine the indirect effects. The bootstrapping method has great power to detect significant indirect effects, even in small samples, since the method does not rely on the assumption of a normally distributed total and indirect effect. Preacher and Hayes ${ }^{97}$ technique and argumentation allow that $X$ can exert an indirect effect on $Y$ through $M$ in the absence of an association between $X$ and $Y{ }^{68}$ In this case, it is recommended that the term "mediator" be avoided and instead call it $X$ 's indirect effect on $Y$ through $M .{ }^{66}$ Indeed, Hayes ${ }^{68}$ advocates to not require a significant total effect before proceeding with tests of indirect effects, since a failure to test for indirect effects in the absence of a total effect might lead researchers to miss potentially interesting and important information.

In this study, the variable "work ability" was used as the dependent variable in the analysis examining the indirect effect of mindfulness on work ability through QOL.
In the direct logistic regression analysis, measuring the impact of mindfulness on RTW, work ability was used as a covariate.

There were no missing data in the two dependent variables RTW and work ability, or in the independent variables QOL, sex, age, and time from intervention. Missing data in the five independents (mindfulness sub-scales), sick-leave length, and length of education varied from $1.3 \%$ to $3.8 \%$. Missing data were found to be MCAR (missing completely at random) with Little's test $(P=0.999)$. Before computing the five mindfulness scales, mean estimates of missing values were calculated from available data and inserted in place of the missing values. In cases where more than two items in a scale were missing, mean calculations were not performed, and the case was considered as missing (one case).

\section{Results}

In Table 1, basic sample characteristics are presented. About half, 47\% (38 participants), of the sample reported having returned to ordinary work and receiving ordinary salary as

Table I Basic characteristics of present sample $(\mathrm{N}=80)$

\begin{tabular}{|c|c|c|c|c|}
\hline \multirow[t]{2}{*}{ Characteristic } & \multirow{2}{*}{$\frac{\text { Total }(\mathbf{N}=\mathbf{8 0})}{\mathbf{N}(\%)}$} & \multirow{2}{*}{$\begin{array}{l}\text { Working } \\
\text { sample }(\mathrm{N}=38)\end{array}$} & \multicolumn{2}{|c|}{ Nonworking sample $(\mathrm{N}=42)$} \\
\hline & & & $\begin{array}{l}\text { Work-related } \\
\text { activity }(\mathrm{N}=24)\end{array}$ & $\begin{array}{l}\text { No activity } \\
(\mathrm{N}=18)\end{array}$ \\
\hline \multicolumn{5}{|l|}{ Age } \\
\hline Mean \pm SD & $47.0 \pm 9.3$ & $48.3 \pm 8.6$ & $46.0 \pm 8.0$ & $45.7 \pm 12.1$ \\
\hline Range & $24-66$ & $30-63$ & $31-66$ & $24-64$ \\
\hline Sex & 80 & & & \\
\hline Males & $7(9)$ & $2(5)$ & $2(8)$ & $3(17)$ \\
\hline Females & $73(91)$ & $36(95)$ & $22(92)$ & $15(83)$ \\
\hline \multicolumn{5}{|l|}{ Work/activity } \\
\hline In work, partly or mainly & $38(48)$ & 38 & 0 & 0 \\
\hline Present sick leave & $5(6)$ & 2 & 2 & I \\
\hline Work preparatory training & $13(16)$ & 0 & 13 & 0 \\
\hline Student/educating & $10(10)$ & 4 & 6 & 0 \\
\hline Vocational rehabilitation & $4(5)$ & 0 & 4 & 0 \\
\hline Job-seeker, active & $8(10)$ & 0 & 8 & 0 \\
\hline \multicolumn{5}{|l|}{ Education } \\
\hline Low education (primary school/high school) & $40(52)$ & $12(32)$ & $18(75)$ & II (6I) \\
\hline High education (university, bachelor or lower/master+) & $38(48)$ & $26(68)$ & $5(2 \mathrm{I})$ & 7 (39) \\
\hline \multicolumn{5}{|l|}{ Main income source } \\
\hline Ordinary salary & $36(45)$ & $36(95)$ & & \\
\hline Work assessment allowance & $35(44)$ & & $23(96)$ & $12(67)$ \\
\hline Other (disability pension, apprentice) & $8(10)$ & $2(5)$ & I (4) & $5(28)$ \\
\hline \multicolumn{5}{|l|}{ Civil status } \\
\hline Single & $5(6)$ & $2(5)$ & I (4) & $2(12)$ \\
\hline Live with partner & $58(73)$ & $30(79)$ & $15(62)$ & $13(72)$ \\
\hline Widow/widower & $3(4)$ & I (3) & I (4) & I (6) \\
\hline Divorced/separated & $14(18)$ & $5(13)$ & $7(29)$ & $2(I I)$ \\
\hline \multicolumn{5}{|l|}{ Currently employed } \\
\hline Yes & $45(56)$ & $38(100)$ & $6(25)$ & I (6) \\
\hline No & $35(44)$ & 0 & $17(7 \mid)$ & $17(94)$ \\
\hline
\end{tabular}

Abbreviation: SD, standard deviation. 
their main income. The other half, 53\% (42 participants), had not returned to ordinary work, and reported receiving work assessment allowance or disability benefit as their main income.

Means, standard deviations, reliability, and correlations between variables in the study are presented in Table 2 . All facets of mindfulness correlated significantly with QOL. The FFMQ global had a moderate correlation with RTW. The "returned to work" group $(\mathrm{N}=37$, mean 27.7, SD 2.9) scored significantly higher at FFMQ global (Hedge's g=0.47, CI 0.02-0.92), compared with the "not returned to work" group ( $\mathrm{N}=42$, mean 26.0, $\mathrm{SD} 4.1$ ). According to Cohen, ${ }^{69}$ this may indicate a medium effect size.

\section{RTW}

Logistic regression analysis was performed to assess the direct impact of mindfulness on the likelihood that respondents returned to work (Table 3 ). The full model containing all predictors was significant, indicating that the model distinguished between working and nonworking respondents. None of the independent mindfulness variables "observe," "describe," and "act aware" made a unique statistically significant contribution to the model. In this study, the significant predictors for RTW were the covariates "work ability" (odds ratio [OR] 2.0, CI 1.41-2.90) and "education level" (OR 6.4, CI 1.56-26.47).

However, when the data were analyzed stratified by education level (Table 4), the "observation" facet of mindfulness made a significant contribution to the model (OR 1.28, CI 1.03-1.59) for "high educated" participants. The model contained three independent mindfulness variables, "observation," "describe," and "act aware," and was significant for the "high educated" individuals, indicating that the model distinguished between working and nonworking respondents in this group.

Bootstrapping analysis examining the indirect effect of mindfulness on RTW through QOL revealed that the model explained $30 \%$ of the variance in RTW. As Table 5 shows, mindfulness positively predicted QOL (path a). Moreover, QOL positively predicted RTW (path b). The model also displayed a non-significant total effect (path c) of mindfulness on RTW. When investigating the indirect effect of mindfulness on RTW through QOL, the BC CI did not cross zero. This proposes an indirect effect of mindfulness on RTW through QOL. That is, a higher level of mindfulness predicted increased QOL, which in turn predicted successful RTW. The covariate "education" also individually predicted successful RTW. That is, individuals who reported a higher level of education also typically reported successful RTW.

\section{Work ability}

Bootstrapping analysis investigating the indirect effect of mindfulness on work ability through QOL, revealed that the model explained $30 \%$ of the variance in work ability. Table 5 shows that mindfulness positively predicted QOL (path a). Moreover, QOL positively predicted work ability (path b). The model revealed a non-significant total effect (path c) of mindfulness on work ability. However, when investigating the indirect effect of mindfulness on work ability through QOL (path ab), the BC CI did not cross zero. This proposed an indirect effect of mindfulness on work ability through QOL. Namely, a higher level of mindfulness predicted a higher level of QOL, which in turn predicted a higher level of work ability. The covariate "sick-leave length" also individually predicted successful RTW.

Table 2 Correlations, means, standard deviations, and reliability of all study measures $(N=80)$

\begin{tabular}{|c|c|c|c|c|c|c|c|c|c|}
\hline Variable & 1 & 2 & 3 & 4 & 5 & 6 & 7 & 8 & 9 \\
\hline I. FFMQ observe & - & $0.60^{\mathrm{a}}$ & 0.09 & -0.03 & $0.54^{a}$ & $0.65^{a}$ & 0.21 & 0.17 & $0.37^{a}$ \\
\hline 2. FFMQ describe & & - & $0.41^{\mathrm{a}}$ & 0.19 & $0.55^{\mathrm{a}}$ & $0.83^{\mathrm{a}}$ & 0.17 & 0.10 & $0.4 I^{\mathrm{a}}$ \\
\hline 3. FFMQ act aware & & & - & $0.48^{\mathrm{a}}$ & 0.18 & $0.64^{\mathrm{a}}$ & 0.15 & 0.13 & $0.37^{\mathrm{a}}$ \\
\hline 4. FFMQ nonjudge & & & & - & 0.15 & $0.56^{\mathrm{a}}$ & 0.14 & 0.14 & $0.31^{\mathrm{a}}$ \\
\hline 5. FFMQ nonreact & & & & & - & $0.69^{a}$ & 0.11 & 0.08 & $0.38^{\mathrm{a}}$ \\
\hline 6. FFMQ global & & & & & & - & $0.23^{b}$ & 0.19 & $0.54^{\mathrm{a}}$ \\
\hline 7. Return to work & & & & & & & - & $0.61^{\mathrm{a}}$ & $0.39^{\mathrm{a}}$ \\
\hline 8. Work ability & & & & & & & & - & $0.45^{\mathrm{a}}$ \\
\hline 9. Quality of life & & & & & & & & & - \\
\hline Mean & 28.7 & 29.7 & 26.6 & 27.2 & 21.8 & 26.8 & & 6.4 & 7.0 \\
\hline SD & 5.6 & 6.2 & 4.9 & 6.1 & 4.4 & 3.7 & & 2.7 & 1.7 \\
\hline$\alpha$ & 0.84 & 0.87 & 0.82 & 0.87 & 0.74 & 0.90 & & & \\
\hline
\end{tabular}

Notes: Mindfulness (FFMQ) subscales: for the nonreact facet, possible range of scores is 7-35. For all other facets, possible range is $8-40$. Return to work, work ability, and quality of life are all single-item measures. ${ }^{a} P<0.01$; ${ }^{b} P<0.05$.

Abbreviations: FFMQ, Five Facet Mindfulness Questionnaire; SD, standard deviation. 
Table 3 Logistic regression analysis for variables predicting work reentry $(\mathrm{N}=75)$

\begin{tabular}{lcclll}
\hline Variable & \multicolumn{6}{l}{ Work reentry } \\
\cline { 2 - 6 } & $\mathbf{B}$ & SE & OR & $\boldsymbol{P}$ & $\mathbf{9 5 \%} \mathbf{~ C I}$ \\
\hline Work ability & $0.7 \mathrm{I}$ & 0.18 & 2.03 & $0.0 \mathrm{I}^{\mathrm{a}}$ & $\mathrm{I} .4 \mathrm{I}-2.90$ \\
Sick-leave length & 0.54 & $0.9 \mathrm{I}$ & $\mathrm{I} .7 \mathrm{I}$ & 0.55 & $0.29-10.12$ \\
Education & $\mathrm{I} .86$ & 0.72 & 6.43 & $0.0 \mathrm{I}^{\mathrm{a}}$ & $\mathrm{I} .56-26.47$ \\
Time & 0.45 & 0.35 & $\mathrm{I} .56$ & $0.2 \mathrm{I}$ & $0.78-3.14$ \\
Observation & 0.07 & 0.09 & 1.07 & 0.47 & $0.89-\mathrm{I} .28$ \\
Describe & -0.04 & 0.08 & 0.96 & 0.63 & $0.83-\mathrm{I} .12$ \\
Act aware & 0.07 & 0.09 & $\mathrm{I} .07$ & 0.46 & $0.90-\mathrm{I} .27$ \\
\hline
\end{tabular}

Notes: $R^{2}=0.47$ (Cox \& Snell), 0.63 (Nagelkerke); Model $X^{2}(7)=48.0, P<0.01$; $\mathrm{I}=$ in work; $0=$ not in work. ${ }^{\mathrm{a}} \mathrm{P}<0.0 \mathrm{I}$.

Abbreviations: $\mathrm{B}$, unstandardized beta coefficient; $\mathrm{Cl}$, confidence interval; OR, odds ratio; SE, standard error of $B$.

\section{Discussion}

This study investigated how mindfulness predicts work reentry. The major finding of the study was the identification of an indirect effect of mindfulness on both RTW and work ability through QOL, supporting the mediation part of the hypothesized model. Mindfulness training may enhance QOL, which in turn may affect work ability and RTW positively. The present findings partially replicate previous research demonstrating a positive relationship between mindfulness and QOL (path a) 2 $^{24}$ and a positive relationship between QOL and RTW (path b) (Table 5). ${ }^{21,70}$ Moreover, the present research expands on these previous findings by identifying QOL as a possible mechanism by which mindfulness is positively associated with work ability and RTW.

As can be seen in Table 5, there was no total effect (path c) of mindfulness on RTW or work ability. This finding was confirmed in the direct logistic regression analysis examining whether some of the five facets of mindfulness predicted RTW. Results from logistic regression analysis (Table 3) revealed no significant differences in level of mindfulness among the participants who had returned and those who had not returned to work after long-term sick leave. This result was somewhat surprising, since mindfulness training is effective in treating depression and anxiety, ${ }^{35,36}$ and pain, ${ }^{38}$ health conditions that cause the majority of long-term sick leave, ${ }^{2,3}$ it was hypothesized that the level of mindfulness would be found to be higher among individuals who had returned to work - assuming health complaints had caused the absence from work. However, the finding underlines the complexity in this multifactorial phenomenon RTW. In the present study, factors being controlled for, work ability and education level, emerged in the forefront and were strong predictors of work reentry.

According to Hayes, ${ }^{68}$ the fact that $X$ (mindfulness) can exert an indirect effect on $Y$ (RTW) through $M(\mathrm{QOL})$ in the absence of a direct association between $X$ and $Y$ becomes understandable when considering that the total effect is the sum of various direct and indirect paths of influence, not all covered in the formal model. For example, two or more indirect paths which carry the effect from $X$ through $Y$ might operate in opposite directions, and in the statistical analysis, two or more indirect effects with opposite signs can cancel each other out and produce a non-significant total effect, despite the presence of indirect effects that are not zero. ${ }^{68} \mathrm{In}$ a complex and multifactorial context like RTW, ${ }^{16,17}$ one must assume many indirect paths operating in opposite directions. Failure to test for indirect effects in the absence of a total effect could have led us to miss important information regarding mechanisms by which mindfulness exerts effects on RTW and work ability.

Work ability operated as covariate in the direct logistic regression analysis and emerged as a strong predictor for successful RTW (Table 3). In other words, individuals who had successfully returned to work typically reported a higher level of work ability than individuals who had not yet returned to work. This finding is consistent with results from the study by Braathen et al, ${ }^{19}$ who found that successful RTW 4 months after an MVRP was predicted by good work ability at baseline and improved work ability at follow-up. Moreover, the covariate "education level" also predicted successful RTW in this sample (Table 3). Participants with a university education level were more likely to report they had returned to work than participants with lower education level. This may indicate that marginalization in the labor

Table 4 Logistic regression analysis for mindfulness variable predicting work reentry, with the data stratified on education ( $N=78)$

\begin{tabular}{|c|c|c|c|c|c|c|c|c|c|c|}
\hline \multirow[t]{2}{*}{ Variable } & \multicolumn{5}{|c|}{ High education $^{\mathrm{a}}(\mathrm{N}=38)$} & \multicolumn{5}{|c|}{ Low education $(\mathrm{N}=40)$} \\
\hline & $\overline{\text { B }}$ & SE & OR & $P$ & $\mathrm{Cl}$ & $\overline{\text { B }}$ & SE & OR & $P$ & $\mathrm{Cl}$ \\
\hline Observation & 0.25 & 0.11 & 1.28 & $0.03^{c}$ & $1.03-1.59$ & -0.06 & 0.09 & 0.94 & 0.53 & $0.78-1.34$ \\
\hline Describe & -0.21 & 0.12 & 0.70 & 0.07 & $0.64-1.02$ & 0.10 & 0.08 & 1.10 & 0.25 & $0.93-1.30$ \\
\hline Act aware & 0.24 & 0.13 & 1.27 & 0.07 & $0.98-1.64$ & -0.01 & 0.07 & 0.92 & 0.92 & $0.86-1.14$ \\
\hline
\end{tabular}

Notes: $\mathrm{R}^{2}$ high education $=0.19$ (Cox \& Snell), 0.27 (Nagelkerke); Model high education $\mathrm{X}^{2}(3)=8.3, P<0.05$; $\mathrm{R}^{2}$ low education $=0.04$ (Cox \& Snell), 0.05 (Nagelkerke); Model low education $\mathrm{X}^{2}(3)=1.7, P>0.05 ; \mathrm{I}=$ in work; $0=$ not in work. ${ }^{a}$ High education = university level; blow education $=$ high school or lower; ${ }^{c} P<0.05$.

Abbreviations: $\mathrm{B}$, unstandardized beta coefficient; $\mathrm{Cl}$, confidence interval; OR, odds ratio; SE, standard error of $\mathrm{B}$. 
Table 5 Mediation analysis for mindfulness on RTW and work ability through QOL $(\mathrm{N}=75)$

\begin{tabular}{|c|c|c|c|c|c|c|c|c|c|c|}
\hline & \multicolumn{5}{|l|}{ RTW } & \multicolumn{5}{|c|}{ Work ability } \\
\hline & \multirow[t]{2}{*}{ Coeff } & \multirow[t]{2}{*}{ SE } & \multirow[t]{2}{*}{ NT P } & \multicolumn{2}{|c|}{ BC $95 \% \mathrm{Cl}$} & \multirow[t]{2}{*}{ Coeff } & \multirow[t]{2}{*}{ SE } & \multirow[t]{2}{*}{ NT $P$} & \multicolumn{2}{|c|}{ BC 95\% Cl } \\
\hline & & & & Lower & Upper & & & & Lower & Upper \\
\hline \multicolumn{11}{|l|}{ FFMQ global (IV) } \\
\hline IV to $M$ (path a) & 0.27 & 0.00 & $<0.01$ & & & 0.27 & 0.05 & $<0.0$ I & & \\
\hline Total effect (path c) & 0.04 & 0.08 & 0.61 & & & 0.05 & 0.09 & 0.55 & & \\
\hline Direct effect (path c') & -0.11 & 0.10 & 0.29 & & & -0.11 & 0.09 & 0.23 & & \\
\hline \multicolumn{11}{|l|}{ Quality of life $(M)$} \\
\hline Direct effect (path b) & 0.70 & 0.25 & $<0.01$ & & & 0.67 & 0.19 & $<0.01$ & & \\
\hline Indirect effect (path ab) & 0.18 & 0.13 & & 0.03 & 0.45 & 0.18 & 0.08 & & 0.04 & 0.37 \\
\hline \multicolumn{11}{|l|}{ Partial effect of CV } \\
\hline Education & 1.94 & 0.62 & $<0.01$ & & & 0.92 & 0.58 & 0.11 & & \\
\hline Sick-leave length & 1.25 & 0.84 & 0.14 & & & 1.59 & 0.72 & 0.03 & & \\
\hline Time from intervention & 0.24 & 0.28 & 0.40 & & & -0.14 & 0.28 & 0.62 & & \\
\hline Model summary $\left(\mathrm{R}^{2}\right)$ & & & $0.30(<0.01)$ & & & & & $0.30(<0.01)$ & & \\
\hline
\end{tabular}

Note: Dependent variables are RTW and work ability.

Abbreviations: BC, bias-corrected; Cl, confidence interval; Coeff, point estimate of effects; CV, covariates; FFMQ, Five Facet Mindfulness Questionnaire; IV, independent variable; $M$, mediator; NT P, normal theory P-value; QOL, quality of life; RTW, return to work; SE, standard error of the point estimate.

market is an underlying problem for the individuals who had not yet returned to work. As shown in Table 1, most of the nonworking sample was in work-related activity. They were able to work, but had not yet entered the labor market. It has earlier been confirmed that people with a low education level need more time to return to work fully. ${ }^{64}$ Mindfulness training alone is unlikely to help "low educated" people to quickly re-enter the labor market. However, descriptive results (Table 1) indicate that $10 \%$ of the participants were in education at follow up, indicating that the MVRP has contributed to facilitating and encouraging further education. The Organisation for Economic Co-operation and Development (OECD) recommends prioritizing skill development for people with low education. ${ }^{71}$

As Table 5 shows, the covariate "sick-leave length" was a significant predictor for work ability. Since reduced selfreported work ability is claimed to receive work assessment allowance for people who have been out of work more than 1 year, it was expected that this variable would give a significant contribution to the model.

Our findings are in line with earlier studies reporting people who had returned to work having a shorter sick-leave length and a job to which to return. ${ }^{62}$ Long history of sickness absence did strengthen all other prognostic factors for non-RTW. ${ }^{65,72}$ Almost one-fifth of the Norwegian population receive income supports due to health problems - nearly everybody who is not working. ${ }^{73}$ Moreover, Brage and Hernes ${ }^{74}$ argue that the OECD in several publications claims that people in Norway are excluded from the labor market by giving them a certification as either sick or disabled. Norway has a generous social protection system, and for many individuals, this welfare-driven strategy has the contrary effect of inequality and exclusion. ${ }^{71}$ Secker et al ${ }^{75}$ identified barriers to employment for people with mental health problems, and found the fear of losing benefits, and fear that leaving benefits for a paid job would not be financially worthwhile, as major barriers to employment. The OECD argues that relatively easy access to long-term sick leave plays to characteristics of mental disorders, like withdrawal and passivity, and thereby excludes individuals from the labor market. ${ }^{71}$ To optimize the efficiency of vocational rehabilitation measures, the OECD recommends defining "rehabilitative program packages for relevant target groups." that investigates not only whether a rehabilitation measure has an effect, but also for whom it has an effect.

Our data suggest that for participants with a university education, mindfulness partially predicts work reentry (Table 4), and the observation facet of mindfulness is significant. Perhaps participants who have not yet returned to work have their attention focused elsewhere, preoccupied with thoughts and worries about being unemployed, pulling their focus away from observing what happens in the moment. The observing facet of mindfulness consists of noticing or attending to a variety of internal or external phenomena (eg, bodily sensations, cognitions, emotions, and sounds); perhaps people can more easily be mindful after they feel better. ${ }^{76}$ It has earlier been confirmed that individuals who had returned to work after an MVRP experienced higher QOL compared with the sick-listed individuals. ${ }^{21}$

\section{Limitations}

This study builds on data from persons referred to an existing governmental funded program by local labor and 
welfare offices. The MVRP was driven by a local vocational rehabilitation enterprise, where the main shareholder is the local municipality. There are limitations to the interpretation of the data. The primary limitation of the present study is the cross-sectional research design. As such, a temporal relationship between mindfulness, QOL, and RTW/work ability could not be conclusively established. This study employed a cross-sectional design and can therefore not provide clear indices of causality direction, ie, whether they are more mindful because they are back at work, or whether higher mindfulness increases the probability of successful RTW. To investigate whether mindfulness training results in higher mindfulness skills for this population, and whether these enhanced mindfulness skills translate to increased probability for RTW, requires a prospective controlled design. The retrospective assessment of the RTW outcome might limit the accuracy of the time to RTW estimate. However, baseline data included information about age, sex, the exact time each participant completed the intervention program, and whether or not the participant had been entitled to a sickness benefit at the start of the program. When analyzing the data, "time from intervention" was controlled for. We did not influence the assignment of persons to the program, so the design lacks strict randomization. However, the participants represent all participants seen over a period of time, and all participants had completed the rehabilitation program. Because of a relatively small number of participants $(\mathrm{N}=80)$, it is possible that generalization from the findings in the study is limited. The population sampled in this study were all on long-term sick leave, therefore generalizability to other samples and settings is limited.

\section{Conclusion}

The current research demonstrates the importance of testing for indirect effects in the complex context of RTW. Rehabilitation programs including mindfulness are increasingly used to treat many of the psychological and physical conditions that are associated with long-term sick leave, but there is a lack of research evidence on the connection between mindfulness training as an intervention and increased work ability and RTW. The data in the present study give evidence on the usefulness of mindfulness applied in the context of RTW, suggesting that mindfulness is indirectly related to both RTW and work ability through QOL. Moreover, for "high educated" participants, the observation facet of mindfulness significantly predicted RTW. The covariates "work ability" and "education level" significantly predicted RTW. An enhancement of education level and qualification for the labor market should be of highest priority for "low educated" people receiving work assessment allowance. How mindfulness might enhance and mediate work ability in a vocational rehabilitation process should be investigated in an experimental design study.

\section{Funding information}

This research project was funded by Durapart AS, Arendal, Norway.

\section{Acknowledgment}

The authors express their gratitude to the 80 participants of the study.

\section{Disclosure}

The authors report no conflict of interests. The authors alone are responsible for the content and the writing of this paper.

\section{References}

1. Alexanderson K, Norlund A. Swedish Council on Technology Assessment in Health Care (SBU). Chapter 1. Aim, background, key concepts, regulations, and current statistics. Scand J Public Health Suppl. 2004;63: $12-30$.

2. Hagen KB, Tambs K, Bjerkedal T. What mediates the inverse association between education and occupational disability from back pain? A prospective cohort study from the Nord-Trøndelag health study in Norway. Soc Sci Med. 2006;63(5):1267-1275.

3. Svebak S, Hagen K, Zwart JA. One-year prevalence of chronic musculoskeletal pain in a large adult Norwegian county population: relations with age and gender - the HUNT study. J Musculoskelet Pain. 2006;14(1):21-28.

4. Henderson M, Harvey SB, Øverland S, Mykletun A, Hotopf M. Work and common psychiatric disorders. J R Soc Med. 2011;105(7):198-207.

5. Bryngelson A. Long-term sickness absence and social exclusion. Scand J Public Health. 2009;37(8):839-845.

6. Gjesdal S, Ringdal PR, Haug K, Mæland JG. Predictors of disability pension in long-term sickness absence: results from a population-based and prospective study in Norway 1994-1999. Eur J Public Health. 2004;14(4):398-405.

7. Allebeck P, Mastekaasa A. Swedish Council on Technology Assessment in Health Care (SBU). Chapter 3. Causes of sickness absence: research approaches and explanatory models. Scand J Public Health Suppl. 2004;63:36-43.

8. Landstad BJ, Wendelborg C, Hedlund M. Factors explaining return to work for long-term sick workers in Norway. Disabil Rehabil. 2009;31(15):1215-1226.

9. Oyeflaten I, Hysing M, Eriksen HR. Prognostic factors associated with return to work following multidisciplinary vocational rehabilitation. $J$ Rehabil Med. 2008;40(7):548-554.

10. Turner JA, Franklin G, Fulton-Kehoe D, et al. Worker recovery expectations and fear-avoidance predict work disability in a populationbased workers' compensation back pain sample. Spine. 2006;31(6): 682-689.

11. Blank L, Peters J, Pickvance S, Wilford J, MacDonald E. A systematic review of the factors which predict return to work for people suffering episodes of poor mental health. J Occup Rehabil. 2008;18(1):27-34.

12. Lagerveld SE, Bültmann U, Franche RL, et al. Factors associated with work participation and work functioning in depressed workers: a systematic review. J Occup Rehabil. 2010;20(3):275-292. 
13. Lötters F, Burdorf A. Prognostic factors for duration of sickness absence due to musculoskeletal disorders. Clin J Pain. 2006;22(2): 212-221.

14. Norlund A, Ropponen A, Alexanderson K. Multidisciplinary interventions: review of studies of return to work after rehabilitation for low back pain. J Rehabil Med. 2009;41(3):115-121.

15. Gabbay M, Taylor L, Sheppard L, et al. NICE guidance on long-term sickness and incapacity. Br J Gen Pract. 2011;61(584):e118-e124.

16. Labriola M, Lund T, Christensen KB, Kristensen TS. Multilevel analysis of individual and contextual factors as predictors of return to work. J Occup Environ Med. 2006;48(11):1181-1188.

17. Krause N, Lund T. Returning to work after occupational injury. In: Barling J, Frone MR, editors. The Psychology of Work Place Safety. Washington DC: American Psychological Association; 2004: 265-295.

18. Kuoppala J, Lamminpää A. Rehabilitation and work ability: a systematic literature review. J Rehabil Med. 2008;40(10):796-804.

19. Braathen TN, Veiersted KB, Heggenes J. Improved work ability and return to work following vocational multidisciplinary rehabilitation of subjects on long-term sick leave. J Rehabil Med. 2007;39(6): 493-499.

20. Sjöstrom R, Alricsson M, Asplund R. Back to work - evaluation of a multidisciplinary rehabilitation programme with emphasis on musculoskeletal disorders. A two-year follow-up. Disabil Rehabil. 2008;30(9):649-655.

21. Lydell M, Marklund B, Baigi A, Mattsson B, Månsson J. Return or no return-psychosocial factors related to sick leave in persons with musculoskeletal disorders: a prospective cohort study. Disabil Rehabil. 2011;33(8):661-666.

22. Berge AR. Hva kan vi laere av deltakerne i PIA-programmet? Delrapport 1 . Kvalitativundersøkelse av deltakernes situasjon, erfaringer og refleksjoner kort tid etter fullført program. Arendal: Rehab - Nor; 2009.

23. Berge AR. Hva kan vi laere av deltakerne i PIA - programmet, og hvordan gikk det med dem det første året etter PIA? Delrapport 2. Kvalitativ undersøkelse av deltakernes situasjon, erfaringer og refleksjoner ca et år etter fullført PIA-program. Arendal: Rehab - Nor; 2009.

24. De Vibe M, Bjørndal A, Tipton E, Hammerstrøm K, Kowalski K. Mindfulness based stress reduction (MBSR) for improving health, quality of life, and social functioning in adults. Campbell Syst Rev. $2012 ; 3$.

25. Kabat-Zinn J. Mindfulness for Beginners: Reclaiming the Present Moment - and Your Life. Boulder, Colorado: Sounds True; 2012.

26. Brown KW, Ryan RM. The benefits of being present: mindfulness and its role in psychological well-being. J Pers Soc Psychol. 2003;84(4): 822-848.

27. Brown KW, Ryan RM, Creswell JD. Mindfulness: theoretical foundations and evidence for its salutary effects. Psychol Inq. 2007;18(4): 211-237.

28. Dane E. Paying attention to mindfulness and its effects on task performance in the workplace. J Manage. 2011;37(4):997-1018.

29. Kabat-Zinn J. Wherever You Go There You are: Mindfulness Meditation in Everyday Life. 10th Anniversary ed. New York: Hyperion; 1994.

30. Shapiro SL, Carlson LE, Astin JA, Freedman B. Mechanisms of mindfulness. J Clin Psychol. 2006;62(3):373.

31. Tolle E. The Power of Now: A Guide to Spiritual Enlightenment. Vancouver, BC, Canada: Namaste Publishing; 1999.

32. Kabat-Zinn J. Full Catastrophe Living: Using the Wisdom of Your Body and Mind to Face Stress, Pain and Illness. 15th Anniversary ed. New York: Bantam Dell; 1990.

33. Kabat-Zinn J. Mindfulness-based interventions in context: past, present, and future. Clin Psychol (New York). 2003;10(2):144-156.

34. Kabat-Zinn J, Massion AO, Kristeller J, et al. Effectiveness of a meditation-based stress reduction program in the treatment of anxiety disorders. Am J Psychiatry. 1992;149(7):936-943.

35. Vøllestad J, Sivertsen B, Nielsen GH. Mindfulness-based stress reduction for patients with anxiety disorders: evaluation in a randomized controlled trial. Behav Res Ther. 2011;49(4):281-288.
36. Lengacher CA, Johnson-Mallard V, Post-White J, et al. Randomized controlled trial of mindfulness-based stress reduction (MBSR) for survivors of breast cancer. Psychooncology. 2009;18(12):1261-1272.

37. Sephton SE, Salmon P, Weissbecker I, et al. Mindfulness meditation alleviates depressive symptoms in women with fibromyalgia: results of a randomized clinical trial. Arthritis Care Res. 2007;57(1):77-85.

38. Esmer G, Blum J, Rulf J, Pier J. Mindfulness-based stress reduction for failed back surgery syndrome: a randomized controlled trial. J Am Osteopath Assoc. 2010;110(11):646-652.

39. Wong SYS, Chan FWK, Wong RLP, et al. Comparing the effectiveness of mindfulness-based stress reduction and multidisciplinary intervention programs for chronic pain: a randomized comparative trial. Clin J Pain. 2011;27(8):724-734.

40. Cohen-Katz J, Wiley SD, Capuano T, Baker DM, Kimmel S, Shapiro S. The effects of mindfulness-based stress reduction on nurse stress and burnout, Part II: A quantitative and qualitative study. Holist Nurs Pract. 2005;19(1):26-35.

41. Ledesma D, Kumano H. Mindfulness-based stress reduction and cancer: a meta-analysis. Psychooncology. 2009;18(6):571-579.

42. Haugstvedt KTS, Hallberg U, Graff-Iversen S, Sørensen M, Haugli L. Increased self-awareness in the process of returning to work. Scand $J$ Caring Sci. 2011;25(4):762-770.

43. Fortney L. Mindfulness for physician burnout. Altern Med Alert. 2011;14(9):104-106.

44. Duchon D, Plowman DA. Nurturing the spirit at work: Impact on work unit performance. Leadersh Q. 2005;16(5):807-833.

45. Petchsawang P, Duchon D. Workplace spirituality, meditation, and work performance. JMSR. 2012;9(2):189-208.

46. Hayes AF. Introduction to Mediation, Moderation, and Conditional Process Analysis: A Regression-Based Approach. New York: The Guilford Press; 2013.

47. Haugli L, Steen E. Kroniske muskel/skjelettsmerter og selvforståelse: utvikling og evaluering av en laringsmodell som vektlegger kroppen som meningsbarer. [Chronic musculoskeletal pain and self-understanding: development and evaluation of a teaching model emphasizing mindfulness and embodiment] [dissertation]. Oslo, Institutt for allmennmedisin og samfunnsmedisinske fag, Institutt for medisinske atferdsfag, Pedagogisk forskningsinstitutt, Universitetet i Oslo; 2001.

48. Steen E, Haugli L. The body has a history: an educational intervention programme for people with generalised chronic musculoskeletal pain. Patient Educ Couns. 2000;41(2):181-195.

49. Brown GI. Human Teaching for Human Learning: An Introduction to Confluent Education. New York: Viking Press; 1971.

50. Merlau-Ponty M. Phenomenology of Perception. 10th ed. London: Routledge and Kegan Paul Ltd; 1996.

51. Beck AT. Cognitive Therapy and the Emotional Disorders. New York: International University Press; 1976.

52. Sviland R, Råheim M, Martinsen K. Touched in sensation - moved by respiration. Scand J Caring Sci. 2012;26(4):811-819.

53. Houge NH. [Braatøy and psychomotor physiotherapy]. Tidsskr Nor Laegeforen. 2001;121(4):505-505. Norwegian.

54. Folketrygdloven. Lov om folketrygd (folketrygdloven). 1997. Available from: http://lovdata.no/dokument/NL/lov/1997-02-28-19. Accessed November 19, 2013. Norwegian.

55. Dundas I, Vøllestad J, Binder PE, Sivertsen B. The Five Factor Mindfulness Questionnaire in Norway. Scand J Psychol. 2013;54(3): 250-260.

56. Baer RA, Smith GT, Lykins E, et al. Construct validity of the Five Facet Mindfulness Questionnaire in meditating and nonmeditating samples. Assessment. 2008;15(3):329-342.

57. Tuomi K, Ilmarinen J, Jahkola A, Katajarinne L, Tullki A. Work Ability Index. 2nd revised ed. Helsinki: Finnish Institute of Occupational Health; 1998.

58. Ahlstrom L, Grimby-Ekman A, Hagberg M, Dellve L. The work ability index and single-item question: associations with sick leave, symptoms, and health - a prospective study of women on long-term sick leave. Scand J Work Environ Health. 2010;36(5):404-412. 
59. El Fassi M, Bocquet V, Majery N, Lair ML, Couffignal S, Mairiaux P. Work ability assessment in a worker population: comparison and determinants of work ability index and work ability score. BMC Public Health. 2013;13:305.

60. Cantril H. The Pattern of Human Concerns. New Brunswick, NJ: Rutgers University Press; 1965.

61. Diener E. Subjective well-being. Psychol Bull. 1984;95(3):542-575.

62. Ahlgren Å, Bergroth A, Ekholm J, Schüldt K. Work resumption after vocational rehabilitation: a follow-up two years after completed rehabilitation. Work. 2007;28(4):343-354.

63. Marnetoft SU, Selander J, Bergroth A, Ekholm J. Factors associated with successful vocational rehabilitation in a Swedish rural area. J Rehabil Med. 2001;33(2):71-78.

64. Huijs J, Koppes L, Taris T, Blonk R. Differences in predictors of return to work among long-term sick-listed employees with different self-reported reasons for sick leave. J Occup Rehabil. 2012;22(3): 301-311.

65. Alavinia SM, Van Den Berg TIJ, Van Duivenbooden C, Elders LAM, Burdorf A. Impact of work-related factors, lifestyle, and work ability on sickness absence among Dutch construction workers. Scand J Work Environ Health. 2009;35(5):325-333.

66. Preacher KJ, Hayes AF. SPSS and SAS procedures for estimating indirect effects in simple mediation models. Behav Res Methods Instrum Comput. 2004;36(4):717-731.

67. Preacher KJ, Hayes AF. Asymptotic and resampling strategies for assessing and comparing indirect effects in multiple mediator models. Behav Res Methods. 2008;40(3):879-891.
68. Hayes AF. Beyond Baron and Kenny: statistical mediation analysis in the new millennium. Commun Monogr. 2009;76(4):408-420.

69. Cohen JM. Statistical Power Analysis for the Behavorial Sciences. 2nd ed. New York, NY: Academic Press; 1988.

70. Sjostrom R, Alricsson M, Asplund R, Nordenmark M. Back to work - a two-year outcome of a multidisciplinary rehabilitation programme focused on physical function and pain. Disabil Rehabil. 2009;31(3):237-242.

71. OECD. Mental Health and Work: Norway. Paris: OECD Publishing; 2013.

72. Dekkers-Sánchez PM, Hoving JL, Sluiter JK, Frings-Dresen MHW. Factors associated with long-term sick leave in sick-listed employees: a systematic review. Occup Environ Med. 2008;65(3):153-157.

73. Duell N, Sing S, Tergeist P. Activation Policies in Norway. Paris: OECD Publishing; 2009.

74. Brage S, Hernes T. Medisin, helse og NAV [Medicine, health and NAV]. In: Hernes T, Haavorsen P, Saglie T, editors. Arbeidsinkludering. Om det nye politikk- og praksisfeltet $i$ velferds-Norge. Oslo: Gyldendal Akademisk; 2010. Norwegian.

75. Secker J, Grove B, Seebohm P. Challenging barriers to employment, training and education for mental health service users: the service user's perspective. J Ment Health. 2001;10(4):395-404.

76. Baer RA. Assessing Mindfulness and Acceptance Processes in Clients. Oakland: New Harbinger Publications; 2010.
Psychology Research and Behavior Management

\section{Publish your work in this journal}

Psychology Research and Behavior Management is an international, peerreviewed, open access journal focusing on the science of psychology and its application in behavior management to develop improved outcomes in the clinical, educational, sports and business arenas. Specific topics covered include: Neuroscience, memory \& decision making; Behavior

\section{Dovepress}

modification \& management; Clinical applications; Business \& sports performance management; Social and developmental studies; Animal studies. The manuscript management system is completely online and includes a quick and fair peer-review system. Visit http://www.dovepress. com/testimonials.php to read real quotes from published authors. 